The mechanism of blistering is obscure. Although its onset in relation to high-dose frusemide is extremely suggestive, the blistering tendency subsides in weeks or months, irrespective of whether large doses of frusemide are continued or not. It is tempting to speculate that frusemide interferes with tissue metabolism in the region of the dermal-epidermal junction in a manner that depends on light exposure, inducing what is clinically an acquired form of epidermolysis bullosa.

We are grateful to Professor A Goldberg who arranged for the porphyrin studies.

${ }^{1}$ Ebringer, A, Adam, W R, and Parkin, J D, Medical fournal of Australia, $1969,1,768$.

2 Gibson, T P, and Blue, P, fournal of the American Medical Association, 1970, 212, 1709.

${ }^{3}$ Fellner, M J, and Katz, J M, Archives of Dermatology, 1976, 112, 75.

Royal Infirmary, Glasgow G4 OSF

A C KENNEDY, MD, FRCP, professor of medicine

A LYELL, MD, FRCP, consultant dermatologist

\section{Comparative trial of two enterostomy sealants}

Some 5000 colostomies and 930 ileostomies are created yearly, ${ }^{1}$ yet no controlled trials have been reported on preparations for maintaining a watertight seal between the enterostomy appliance and the skin around the stoma. The two most important factors are the quality of adhesion and the incidence of skin sensitivity, and with these in mind we have carried out a cross-over trial of two commonly used sealants, Reliaseal and Stomahesive.

\section{Patients, methods, and results}

The trial was supervised by GE, who is trained in stoma care. Forty patients ( 21 women and 19 men) who agreed to the trial were given printed details and their general practitioners informed. They were then divided into two groups: those with established stomas and those in the immediate postoperative period. Half of the patients in each group were allocated at random to Reliaseal and half to Stomahesive, with cross-over at monthly intervals until at least four changes had been completed. Follow-up was from four to nine months. Since adhesion and sensitivity are related to the layer next to the skin no attempt was made to influence the type of appliance worn although this was noted. Patients recorded in a daily diary the frequency of emptying and changing their appliances, and skin reaction or soreness, and any other comments regarding the appliance. If skin sensitivity was observed the sealant was changed to the other type and a patch test set up against the one that had produced the reaction.

Altogether 35 patients preferred Stomahesive and five Reliaseal (see table). Reasons for preferring Stomahesive included fewer changes, greater security because of better adhesiveness, particularly over the uneven surface of an obese abdomen, greater comfort, and flexibility of size. Reasons for preferring Reliaseal were that it is less bulky and easier to clean off the skin. Skin sensitivity with a positive patch test reaction was recorded in three patients with Stomahesive and eight with Reliaseal.

\section{Comment}

Patients in apparently similar clinical conditions vary considerably in their preference for particular enterostomy appliances. For patients with established stomas it is not possible to predict nor profitable to try to influence their individual reactions to a particular appliance. It is important, however, to have objective information on the incidence of skin sensitivity, and in the early postoperative period, when the psychological effect of stoma problems is greatest, the patient should be given the appliance most likely to prove satisfactory.

Preference of patients for one or other sealant

\begin{tabular}{|c|c|c|c|c|}
\hline & \multicolumn{2}{|c|}{ Stomahesive } & \multicolumn{2}{|c|}{ Reliaseal } \\
\hline & Men & Women & Men & Women \\
\hline $\begin{array}{l}\text { Established colostomy ... } \\
\text { Postoperative colostomy } \\
\text { Established ileostomy ... } \\
\text { Postoperative ileostomy.. }\end{array}$ & $\begin{array}{l}3 \\
6 \\
1 \\
5\end{array}$ & $\begin{array}{l}8 \\
2 \\
8 \\
2\end{array}$ & $\begin{array}{l}3 \\
1\end{array}$ & 1 \\
\hline Total & \multicolumn{2}{|c|}{35} & \multicolumn{2}{|c|}{5} \\
\hline
\end{tabular}

The preference for Stomahesive in the early postoperative period (see table) was related mainly to the oedematous stoma at this stage. This requires a larger internal diameter of the seal with a smaller area of contact, which is less important with Stomahesive because of its superior adhesive quality.

We are grateful to the nursing and surgical staff of the University Hospital of Wales for their co-operation, and to the department of dermatology for help with the patch tests. We are indebted to E R Squibb and Sons Ltd for support in setting up the trial.

${ }^{1}$ Office of Population Censuses and Surveys, Hospital Inpatients for the Year 1967. London, HMSO, 1970.

University Department of Surgery, Welsh National School of Medicine and the University Hospital of Wales, Cardiff

GILL EVANS, SRN, sister

R A B WOOD, MB, FRCS, lecturer

L E HUGHES, FRCS, FRACS, professor 